\title{
TRES DOCUMENTOS DE LOS SIETE PUEBLOS ORIENTALES 1928-1929.
}

\section{Oscar Padron Favre*}

El último capítulo del ciclo vital de los Siete Pueblos Orientales esta determinado por la emigración - en compañia de algunos pueblos Occidentalesal Estado Oriental.

Este acontecimiento, ocurrido cuando finiquitaba el año 1828, no ha merecido aún la debida atención de la historiografía brasileña ni - caso aún más reprochable - de la uruguaya. Por esta razón es frecuente ver en autores modernos, que fugazmente transitan por el tema, como se repiten conceptos tendenciosos elaborados por memorialistas o historiadores en el pasado siglo.

Sin embargo, la investigación acuciosa de esos hechos revela una realidad diferente, sobre todo si tomamos en cuenta la propia palabra de sus principales protagonistas: los indios misioneros.

El éxodo de este pueblo, y su consecuente radicación en el naciente Estado Oriental, motivó a las autoridades indígenas redactar una importante serie de documentos que arrojan reveladora luz sobre los móviles y sentimientos de esa nación al tomar tal resolución.

Personalmente, conozco algo más de una docena de esos testimonios, los cuales permanecen, en su mayor parte, inéditos o poco conocidos para la historiografía misionera. Redactados en guaraní, fueron inmediatamente traducidos al español, quedando la primera versión en manos misioneras y la segunda en los archivos públicos o privados del Uruguay.

Por esta causa en la casi totalidad de los casos sólo se conservan las versiones en español de los mismos. ${ }^{1}$

Creo interesante, en esta oportunidad, transcribir tres de dichas piezas, que podrían indentificarse bajo los títulos de: "Exposición de motivos para emigrar al Estado Oriental", 1828; "Acta de designación de Diputados para

Estudos Ibero-Americanos. PUCRS, v.XVII, n.2, p.17-29, dezembro, 1991 
establecer la reincorporación de los Siete Pueblos al Estado Oriental", 1828; "Solicitud para el retorno de los jesuítas", 1829.

Pese a su distinta motivación los tres coinciden en algunas características de no poca importancia para acercarnos a las ideas, sentimientos y anhelos de esta sufrida población. Revelan, además, la existencia en la comunidad misionera de un claro sentido de identidad nacional, de clara conciencia de lo que fue y ęra, de sus orígenes, de sus bienes y derechos y de su fatal peripecia histórica. Sus palabras se transforman, al final del ciclo histórico misionero, en un elocuente veredicto sobre el significado de la obra jesuítica.

Mucho se ha escrito y se escribe sobre la experiencia misional jesuítica con los guaraníes, pero en esos estudios o comentarios pocas veces aparece, o se le reconece importancia, a la palabra del propio indígena, pese a que los archivos de la región plantense poseen importantes testimonios al respecto.

Documento n. 1 - "Exposición de motivos para emigrar al Estado Oriental".

Este documento, fechado en las márgenes del Ibicuy el 16 de Diciembre de 1828 , es posible que haya sido redactado antes de cruzar el citado río, tradicionalmente tomado como límite sur de las Misiones Orientales.

Su traducción al español revela la participación de una pluma nada torpe, integrante, posiblemente, del círculo que rodeaba al General Fructuoso Rivera, destinatario del documento.

Fue publicado por primera vez en el folleto titulado "Errores que contiene la Memoria sobre la decadencia de las Misiones Jesuíticas, que ha publicado en la ciudad del Paraná el Dr. Dn. Martín de Moussy: en el presente año de 1857; impugnados por D. Juan Manuel de la Sota", de la autoría de este último, historiador oriental. ${ }^{2}$

El citado De la Sota manifiesta en determinado momento:

"Hoi, pues, que la Memoria de las Misiones Jesuíticas tiende a llamar la atención de Europa sobre rejiones de las cuales dice se habló tanto en un tiempo y que después han caído en olvido

...

me ha constituído en el forzoso deber de depurar los errores, las inesactitudes, incosecuencias y faltas, ya en el orden cronológico como en el histórico que en ellas observo" 3

Pasa entonces a enumerar una serie de objeciones, incluyendo el documento que nos ocupa en la objeción no 12. En ella De la Sota impugna las 
palabras de De Moussy cuando expresa que con la empresa del General Rivera:

"los indios fueron despojados de la mayor parte de sus ganados, robados por los vencedores, las iglesias vieron desaparecer sus alhajas: más preciosas, y todos los desórdenes, consecuencia natural de la conquista, se cometieron en medio de una población hasta ahora tan pacífica"4

De cómo llegó el documento a manos del citado historiador, él mismo se encarga de explicarlo cuando dice:

"En tal alternativa, los indígenas para dejar a salvo la reivindicación de sus derechos para con la el Imperio, al abandonar sus pueblos dirijieron al jeneral del ejército del Norte una solemne protesta, de la que bajo su firma se dignó el finado jeneral franquearnos una copia" 5

Texto del documento

"Exmo. Sr. General del Ejercito del Norte

Si veinte años de una opresión sin causa, ni medida no autorizan al hombre, que nacio libre, para huir de sus verdugos, nosotros sin duda hemos cometido un gran delito en abandonar la tierra de nuestros mayores, aquella en donde ellos reposan y nosotros nacimos, por trasladarnos a un pais, cuyo idioma apenas conocemos, cuyas leyes ignoramos y cuyo carácter no sabemos si había desjenerado en el trascurso del tiempo y los sacudimientos de una revolución, que todo lo desfigura.

Este paso es terrible: pero cuanto más lo parezca, otro tanto recrecerá a los ojos de todo hombre pensador, la idea de nuestra desgracia, por que icual es aquel que se decide a perder una patria, qué la naturaleza colmó de todos sus dónes? ¿cuál el que se resigna a dejar un clima benigno y una tierra siempre pronta a pagar con usura los sudores trabajador?... ¿ ¿cuál de nosotros, Exmo. Sr., que volvería la espalda para siempre á esos bosques, que el estandarte de la cruz convirtió en templos y ciudades, sino se sintiera impedido de una causa más fuerte que el grito de la naturaleza y las inspiraciones de la religión?

Pero no es preciso abandonarse a conjeturas. Los hechos hablan y V. E. los tiene a la vista. Esas Misiones que todavía en 1801 eran un monumento grandioso del poder del Evangelio, del saber y de la industria ino las ha transitado V. E. temblando, porque sus ruinas amenazan de cerca a todo el que las visita? ¿A la curiosidad con que el ejército del Norte, que examinaba los recintos de cada pueblo en la 
invasión: no se sucedían rapidamente el asombro, la pena y el odio a los autores de tanto estrago?...

Al paso que los templos desnudos y abandonados a todas las injurias del tiempo descubren la profanación de nuestro santuario, las casas de nuestros opresores servidas de nuestros hijos, prueban bien que nuestra libertad, como descendientes del Guaraní reducido pero no conquistado, se ha convertido en una esclavitud la más ignominiosa. pues que ni el padre puede salvar su prole de la servidumbre doméstica, ni la madre preservarla de humillantes castigos... Los niños jimen bajo el azote de sus amos: los adultos perecen de fatiga y las virjenes, que el jesuíta endiosaba, el portugues las destina en edad prematura para cebo de una cansada laseavia.

Así la nación envilecida ha perdido gradualmente el amor a la familia, la aplicación al trabajo, el gusto a las artes, y de sus virtudes jeniales solo conserva una piedad, que apenas puede deistinguirse de la superstición más absurda.

Pero nosotros hablamos de una Nación, cuando apenas existen sus vestigios: porque la misma codicia que devoró nuestros ganados, que dilapidó nuestros cofres, que pilló ! oro de nuestros templos, que se apropió nuestras casas, o las derribó para levantar las suyas; esa misma dispersando los pueblos y deportando la juventud a climas ardientes o haciéndola servir en sus guerras, o abrumándola en tareas insoportables, estinguió la reproducción y en el corto espacio de veinte años destruyó cuatro mil familias, que enriquecían y hacían respetables a sus propios enemigos las Misiones Orientales.

Una conducta tan desusada, tan cruel, tan impía no se crea que ha sido el efecto de casuales extravíos, a que están expuestos todos los gobiernos, y en especial aquellos, que tienen una complecsión, ó viciosa o corrompida.

El Guaraní y sus pueblos eran destruídos porque así lo había decretado la política, y porque así era preciso para que las ricas posisiones de los pueblos, sus ganados y plantaciones cayeran en manos del portugués, y sus vasallos decorados con diversos títulos entrasen a gozar, sin temor de ser reconvenidos un día por nosotros ó por la nación, a que fueron arrancados en 1801.

Así que el temor de este exterminio inevitable há mucho tiempo que nos hacía pensar en nuestra defensa a nuestra evasión pero recordamos tarde. Y á no haber enviado la Providencia al ejército del Norte, hasta los vestigios del império guaranítico habrían desaparecido mui pronto, como los sembrados despues de una inundación repentina.

El Ejército del Norte nos ha salvado. Su presencia, su conducta y su lenguaje renovaron en nosotros la memoria de aquelos días, en que nuestros pueblos respiraban la paz y 
el contento de un existir dividido entre las provechosas fatigas dela industria y las delicias del culto.

Entonces, Exmo. Señor, el silencio que ahora espanta, era el bullicio de las sociedades activas, y la capital de los siete pueblos no era no, ese montón de ruinas sombrías, que apenas ha podido dar un asilo poco decente al Gobierno de toda la Provincia!!. Entonces la desnudez del indígena no alarmaba la honestidad: su semblante no descubría la humillación: su vivir no era, en fin, el de unos miserables, que enfadan por la estupidez o el desaliño.

Los campos estaban poblados de haciendas numerosas y cubiertos de plantaciones, cuyos productos alimentaban los talleres y el comercio de las Misiones con todos los pueblos de ambas orillas del Paraná. Entonces una moral severa alejaba los vicios de entre nosotros, y una piedad, bien entendida hacía de la Relijión el móvil de los regocijos públicos. Los templos repetían diariamente los conciertos de nuestras músicas; y las festividades de nuestros Santos Patronos eran días igualmente marcados para el joven y el anciano. Porque todos hallaban en ellas atractivos adecuados a su edad y sus pasiones. V. E. quiso hacer revivir estos días venturosos: V.E. alcanzó a más, porque V.E. llamó la Provincia de Misiones al goce de todos sus derechos: le dió una representación en que fue reconocido el guaraní como el Señor del terreno que habita. V.E. nos reincorporó a la República Arjentina, a esos pueblos, es decir, de donde el Jesuíta partió por la primera vez, para reconocer los bosques impenetrables del Uruguay, reunir sus habitantes, civilizarlos y reducirlos.

Nosotros creímos que esta obra sería tan durable como su beneficencia y su justicia: pero bien pronto V.E. mismo nos hizo entender que la República Arjentina no quería protejernos o no podía sustentar nuestra voluntaria reincorporación, sin faltar a sus compromissos con el imperio del Brasil... En semejante conflicto todos los indígenas, recobrando el brío de sus antepasados no trepidaron en hacer el juramento que nosotros ahora repetimos y deseamos que grave V.E. en un monumento humilde, como nuestra situación, pero capaz de pasar a la posteridad más remota, como un testigo de las injusticias que hemos sufrido, de los derechos que reclamamos, y de la resolución, con que en pos de V. E. hemos marchado hasta las márjenes del Ibicuhy.

Nosotros Exmo. Sr. cansados de sufrir las vejaciones del viejo Portugal y del moderno Brasil, declaramos, que no reconosemos en esta nación otro derecho que el de la fuer$\mathrm{za}$, para proporcionarse nuestro país en 1801, para depredarlo sucesivamente y convertirlo en una mansión de esclavos, sacrificados á la codicia y á las obsenidades de su señor. 
Declaramos que la propriedad del territorio de Misiones, así como nunca, por nosotros, ni por nuestros mayores fue cedida a ningún potentado estranjero, así ninguno pudo cederlo a otro por un derecho lejítimo. pues que éste suelo era poseído por nuestros mayores y por ellos fue cultivado, a condición únicamente de creer en Jesu Cristo y reconocer la dinastía de los reyes de Castilla.

Declaramos que sí en virtud de este contrato, nuestros mayores depusieron las armas, si abandonaron los bosques, si abrazaron al jesuíta: si le siguieron, y se postraron con él ante la cruz del redentor del universo, esto no fue, ni pudo ser, para que la España un día los vendiera a su política o el Portugal los redujera a una condición tan miserable como la del africano, pero más cruel, porque es más injusta, más dura porque es más infame.

Declaramos que, en fuera de tales injusticias y defensa de nuestra propia existencia, amenazada de un esterminio meditado, hemos resuelto trasladarnos al nuevo Estado Oriental, con aquella parte de nuestras propiedades que las circunstancias nos permiten esportar y conducir, poniéndolo todo bajo la protección de V.E. y del ejército de su mando, para que lo proteja, defienda y ampare, hasta ponerlo en salvo de todo riesgo.

Y respecto a que nuestra emigración es un partido estremo adoptado en el único momento de libertad que hemos gozado después de nuestra esclavitud, sin tiempo ni medios para disponer de nuestras tierras, protestamos reclamar su valor toda vez que no sea posible obtener su restitución, cono una propiedad usurpada a la antigua España, y á los primitivos señores del territorio de todas las misiones del Uruguay.

Declaramos que nuestro ánimo es unirnos al Estado Oriental, conservando solo aquellos privilejios y escenciones que fueren conciliables con las mismas instituciones que el mismo Estado adoptare para el gobierno y comun felicidad de sus habitantes, hasta tanto que, haciéndonos justicia el Brasil, o recuperada nuestra patria por otro arbitrio lejítimo, podamos ocuparnos de su destino futuro, siempre en unión con los pueblos orientales.

Declaramos que para estas deliberaciones no han obrado en nosotros otros principios que los espuestos, ni en ellas ha tenido otra parte el ejército del Norte que la de un amigo, un protector conmovido de nuestros males y ansioso de remediarlos.

Que nosotros hemos dejado nuestros pueblos espontáneamente y marchado hasta aquí, sin más impulso que nuestro deseo de hacermos justicia, y dar al mundo una prueba incontestable de que jamás voluntariamente hemos renunciado de esa libertad que nos fue garantida por los 
reyes de Castilla, como un derecho peculiar intranferible de los aborijenes del nuevo mundo.

Por último, Exmo. Señor, haciendo ante el Cielo y la América entera una protesta solemne contra todos y cualquiera actos, que durante la esclavitud pueden haberse estorquido (sic) á la imbecilidad o ignorancia de nuestros compatriotas para lejitimar la conquista de nuestro suelo nativo, ó la apropiación de las riquezas, acumuladas por nuestra industria hasta 1801 , pedimos a V.E. que sin pérdida de instantes, se digne elevar esta nuestra súplica al gobierno soberano Oriental, que para promoverla en todos los sentidos se nos permita nombrar ajentes o apoderados, que investidos de la representación conveniente parezcan ante aquella autoridad, le presten homenaje, y nos prescriban, según sus mandatos, la conducta que en adelante deban seguir los Siete pueblos de las Misiones Orientales y sus ascriptos.

Campo de los Siete Pueblos en las márgenes del Ibicuy. Diciembre 16 de 1828.

- Es conforme a la traducción del original que hice sacar a los fines consiguientes por los peritos en el idioma Guaraní que lo suscriben.

Fructuoso Rivera."

Documento n.0 2 - "Acta de designación de Diputados para establecer la reincorporación de los Siete Pueblos al Estado Oriental".

Este documento está fechado dos días después que el anterior, o sea el 18 de Diciembre de 1828 , también en las márgenes del Ibicuy, aún cuando es posible suponer que haya sido redactado una vez cruzado el citado río.

Los Diputados indios, Tiraparé, de San Borja, y Yatuy, de San Nicolás, ya habían participado con tal caráter en el Congresso de San Borja. ${ }^{6}$ Fernando Tiraparé jugará un rol muy importante durante la posterior vida misionera en el Uruguay, constituyéndose en el último Corregidor de la comunidad india. ${ }^{7}$

Es posible, también, precisar el origen de la mayor parte de los indígenas que signan el documento. Egidio Tariuma, Corregidor de S. Juan, Leandro Mendare, Corregidor de Santo Angel; Supriano Atavi, Corregidor de S. Miguel y Estevan Abave, Corregidor de San Luis.

El documento en cuestión, fue publicado por el historiador uruguayo Agustín Beraza en su trabajo "Rivera y la independencia de las Misiones" (Montevideo 1971). Sin embargo para su publicación he utilizado la copia original firmada por las autoridades misioneras existente en el Archivo Gene- 
ral de la Nación de Montevideo. Eso ha permitido corregir algún error de la versión antes citada. ${ }^{8}$

Texto del documento:

Alos diez y ocho días del Mes de Diciembre de mil ochocientos veinte y ocho.

Los Corregidores, Tenientes Corregidores y Casiques de los Siete Pueblos delas Miciones Orientales, reunidos enlas margenes del Ibicuy, vaxo la Protección del Exercito del Norte, y con animo resuelto de trasladarse al Estado Oriental, y someterse a sus inistituciones; dijeron, que haviendo elevado sobre estos objetos la suplica combeniente al Exmo. Sor. Gral. en Xefe D. Fructuoso Rivera, y obtenido asu retirada, el permiso de tomar todas las medidas que se creyecen oportunas, y especialmente como una de éllas el nombrar personas, que imbestidas del caracter combeniente, puedan personarse ante el Gobierno del dicho Estado Oriental, prestarles homenages a nombre de dichos Pueblos, y promover la aceptación del pacto, con que desean hacer efectiva (en quanto hoy pueda serlo) su reincorporación por que se pronuncian expontaneamente ante el Congresso dela Provincia reunido en S. Borja para este efecto; venían en nombrar alos Sres. Doct.r D. Lucas Jose Ovez, diputado D. Fernando Tirapared, y al de igual Clase D. Vicente Iatuy, a quienes confieren todo el poder y facultad que mas necesario fuese ahí para los fines aquí expresos, como para todo lo que en su acecucion demandare, principal, o accidentalmente, siendo su deceo que procedan a la mayor brevedad, áformarun pacto que sirva de vase ala dicha reincorporación y establecimiento delos Siete Pueblos, en el Territorio del Estado Oriental, sin renuncia o menoscavo de sus Derechos, al que desan en la Provincia de Miciones, y deseando se miren siempre como una propiedad dela Nacion Indígena que los Poblo, cultivo, mantubo y Governó hasta 1801, en conformidad delas Leyes del caso, por que, asi en esto, como en la concervación de a quellos privilegios que fueren conciliables con las instituciones del Estado Oriental, quieren los Pueblos que los Señores Representantes nada pacten que pueda Ofender ala felididad de sus venideros.

En cuya virtud, declarando que todo lo hecho en tal sentido, lo aprueban desde áhora, lo ratifican, y lo dan por tan valedero, como si con ellas directamente se entendiere, ordenaron que se dieren alos Sres. Diputados, copia autentica de esta Acta, con todas las de su referencia; que les sirva de Diploma suficiente para representar ala Provincia de Miciones, y promover sus derechos, segun, y como por ella queda determinado, pero sim perjuicio de que los mismos 
Corregidores, y Cavildos puedan darles mas amplias inistrucciones todas las veces que el caso lo requiera.

$\mathrm{Y}$ en su cumplimiento nos los que subscrivimos sacamos la precente, que es conforme al original de su contesto.

\begin{tabular}{|c|c|}
\hline $\begin{array}{l}\text { JOSE FRAN. }{ }^{c 0} \text { TRAUPA } \\
\text { Correxidor }\end{array}$ & $\begin{array}{l}\text { EGIDIO TARIUMA } \\
\text { Correxidor }\end{array}$ \\
\hline $\begin{array}{l}\text { EUG? ARAPEYU } \\
\text { Correxidor }\end{array}$ & $\begin{array}{l}\text { FERNANDO TIRAPARE } \\
\text { Teniente Correxidor }\end{array}$ \\
\hline $\begin{array}{l}\text { FRANco XI ARAPOTI } \\
\text { Ten te Correx }{ }^{\text {or }}\end{array}$ & $\begin{array}{l}\text { ESTEVAN ABARE } \\
\text { Capn Correg.r }\end{array}$ \\
\hline $\begin{array}{l}\text { D } \text { JUSTINO ACATU } \\
\text { Cacique }\end{array}$ & $\begin{array}{l}\text { SUPRIANO ATAVI } \\
\text { Teniente Correx }^{\text {or }}\end{array}$ \\
\hline $\begin{array}{l}\text { LEANDRO MENDARE } \\
\text { Corregidor }\end{array}$ & $\begin{array}{l}\text { MARIANO CHEMBO } \\
\text { Then }^{\text {te }} \text { Correx }\end{array}$ \\
\hline
\end{tabular}

(firmas originales)

Documento n. 3 - "Solicitud para el retorno de los jesuitas"

En Mayo de 1829 arribaba a la incipiente población misionera de Bella Unión Fray Francisco de Paula Castañeda, sacerdote de dilatada y agitada participación en el proceso revolucionario rioplatense.

Estando Castañeda en Bella Unión, y ante el desolador espectáculo que brindaba el pueblo misionero en su emigración, concidió aquél el proyecto de promover el retorno de los jesuítas para fundar colegios en el territorio de Misiones. En carta de Castañeda al General Rivera, fechada el 25 de Mayo de 1829, le decía:

"Con toda reserva he comunicado a Carriegos un Proyecto magnifico... que quizá será lo único bueno que habremos echo en los diecinueve años de desvaríos"9

El documento que publicamos es una copia original de la petición que elevaron "Los Gefes de los Siete Pueblos de las Misiones" al General Rivera, con el propósito de que éste apoyara y promoviera el retorno de los jesuítas. No consta la fecha del mismo - es posible que sea copia de un borrador pero debe ubicarse, sin duda, en los últimos días de mayo, o primeros de junio, de 1829.

Trasunta el documento el especial gozo que provocó, en la comunidad misionera, la posibilidad de volver a ver en ella la presencia de los recordados Padres jesuítas. 
La copia que doy a conocer se halla en el Archivo General de la Nación, de Montevideo, ${ }^{10}$ y creo, según mis conocimientos, era inédita hasta el presente.

Texto del documento:

Los Gefes de los Siete pueblos de las Misiones, habiendo abandonado nuestros hogares por acogernos bajo el pavellón de la República Oriental, hicimos a V.S. una representación para que se dignase elevarla al Congreso, o Asamblea soberana; en la tal representación manifestabamos las causas que habían dado motivo a transmigrar con nuestros hijos y familias, como también las condiciones y pactos que debían preceder a nuestra incorporación y a nuestro perpetuo establecimiento en las costas del Cuarey.

Por no haber tenido hasta ahora contestación alguna nos reputamos aún como peregrinos, como huespedes, advenedizos, y sin residencia fixa; esta situación nos llena de angustia, y al mismo tiempo nos desalienta en el trabajo que con tanto brío habíamos emprehendido en la población de este suelo, que mas hoy mas mañana habremos se abandonar en el caso de que la República Oriental nos deje sepultados en la incertidumbre angustiadora de lo que somos y de lo que seremos.

No se nos oculta que las gravíssimas atenciones del cuerpo soberano habran impedido o retardado el despacho de nuestras solicitudes, y assi es que hasta ahora no hemos importunado la atención de V.S. sobre este negocio, ni tampoco la importunaríamos ahora si no hubiese ocurrido una circunstancia que para nosotros es importantíssima, y no podemos menos de elevarla al conocimiento de V.S. por que es de mucho momento para consolar a estos siete pueblos, y aun para hacerles olvidar todos sus padecimientos.

Esta inapreciable circunstancia es la de un religioso franciscano qe de viaje para Corrientes se ha hospedado por algunos días en la Bella Unión, y nos ha ilustrado en los terminos que mas abajo expondremos a V.S. con la mayor sinceridad y verdad como a nuestro padre y protector; pero por cuanto no sera V.S. solo el que ha de leer este escrito, no sera fuera de proposito el que antes de referir a V.S. las propuestas, y proyectos del dicho religioso, tratemos de exponer aquí lo que V.S. sabe de nosotros por una larga experiencia.

En efecto: A V.S. le consta que los Guaranis en su transmigración no han reservado para sí otra cosa que las imagenes tutelares de sus pueblos; nada mas han trahido consigo que los ornamentos, los vasos sagrados, las alajas, 
y campanas de sus templos; como también que habiendo echo alto en las orillas del Cuarey se reduxeron a vivir en la inclemencia hasta que se concluyesen las siete capillas, a saber, una grande y seis pequeñas para colocar decentemente las sagradas imagenes, y que no pensaron en construir cuarteles y ranchos sino despues de concluídas las capillas para el culto; por último le consta a V.S. que la campana diariamente nos convoca a todos al templo por mañana tarde y noche para emplearnos en las divinas alabanzas.

Los Guaycurus [sic. Guaranis], Señor general, conservamos de padres a hijos el noble orgullo de haber sido conquistados, y reducidos sin armas, y de habernos sugetado espontanea y libremente al estandarte de la Santa Cruz enarbolado en las manos de unos religiosos que totalmente inermes se presentaron en nuestros bosques; desde entonces hasta el día de hoy nos jactamos de gloriarnos en la inestimable, insigne, preciosissima reliquia de la Santa Cruz, reconociéndola por el adorable instrumento de nuestra redención; desde entonces y sin podernos contener miramos con cierto pasmo y estupor sagrado a los religiosos que nos conquistaron para Jesuchristo, sintiendo un singular gozo y complacencia cuando por fortuna aparece en nuestros pueblos algun religioso, a quien en nuestras primeras vistas somos importantísimos, porque no hay uno de nosotros que no se apresure a besar el Santo habito, acordándonos que si los de esta preciosa librea no hubieran visitado en el siglo quince a nuestros padres, nosotros ahora estubieramos sepultados en las tinieblas de la barbarie, del gentilismo y de la idolatría.

Lo poco que ahora decimos, y todo lo demas casi imenso que pudieramos añadir, y de que V.S. mismo es testigo, basta y aun sobra para instruir el animo de la soberana asamblea, y para que cuantos lean este escrito se persuadan, y conozcan de lo doloroso que nos es el no tener un sacerdote que presida nuestros cultos religiosos.

V.S. sabe muy bien que todos los días festivos nos juntamos en la Iglesia, y que al son de nuestros instrumentos musicos entonamos el introito, la gloria, el credo y los demas himnos; pero todos estos actos al paso que nos consuelan, avivan más y más nuestro sentimiento por la falta de nuestros antiguos ministros; este sentimiento se ha redoblado en nosotros cuando hemos llegado a saber que en esta república oriental se esta ya acabando el clero secular, y regular sin esperanza de recobrar tamaña pérdida.

Sin ministros que nos repartan el pan de la doctrina christiana, es de temer que nuestros hijos olviden lo necesario de la fé, lo precioso de la oración, lo indispensable de la 
penitencia; es de temer que ignoren la eficacia y virtud de los sacramentos, como también la importancia y necesidad de frecuentarlos, hasta el extremo de venir a ser como los gentiles, que viven y mueren sin esperanza, y que ni conocen nuestra religion, ni la desean, ni la solicitan, ni la aman, ni la poseen, sino que antes bien la desprecian, la aborrecen $\mathrm{y}$ persiguen.

Verdad es que los Guaranis en los días festivos convocamos a toda la población a la morada de sus gefes respectivos para que oigan de la voca de sus superiores la explicación de nuestros misterios; pero esto no es bastante, ni los gefes, por esto dexaremos de ser responsables, si nuestro celo no se abanza a solicitar por todos medios y modos un sacerdote cuando menos para cada uno de nuestros pueblos.

\section{OPORTUNA LLEGADA DEL REVERENDO PADRE JUVILADO Y DEFINIDOR FR. FRAN. CO CASTAÑEDA AL PUEBLO DE LA BELLA UNION}

Cuando estabamos los Guaranies mas engolfados en la ponderación de nuestra infausta suerte llegó a nuestra población el Rdo Padre Fr. Franco admirándose mucho de lo que habíamos trabajado en $\tan$ breve tiempo, y con los ojos azorados en lagrimas nos exortaba a la constancia, ultimamente se despedió de nosotros despues de haber bautizado nuestros hijos, y predicandonos todos los domingos; le expusimos lo afligidos que estabamos por no encontrar un sacerdote, y el Padre nos contestó lo siguinte:

"Yo, hijos, me animo a ir a Roma para visitar en vues"tro nombre las Iglesias de la Capital del Orbe Cristiano, y "para hacer en vuestro nombre una ofrenda al Sumo Pontí"fice, que consistirá en la donación de alguna tierra para "que su santidad funde en ellas uno o más colegios de reli"giosos Jesuitas y creedme que dentro de dos años me "tendreis en vuestras misiones con todos los religiosos que "fueren necesarios para vuestro consuelo, el unico que po"drá oponerse a esta medida, pero a mi cuenta queda el per"suadir, a Fernando Legítimo, y convencerlo de que yo ni "quito rey ni pongo rey, sino que favorezco a unos in"felices = Comunicad esta mi propuesta a vuestro general y "protector Rivera para que obtenga la licencia de mis "prelados y el beneplácito de la Asamblea soberana bajo "cuyo pabellón os habeis acogido, y cuando todo esté "allanado disponed de mi en la inteligencia de que yo para "toda esta empresa no pido más que cuatrocientos pesos "para conducirme hasta el puerto de la Civitavechia; mi "regreso y la conducción de los religiosos hasta Misiones "corre de mi cuenta". 
Estas fueron las palabras conque se despidio el $\mathrm{R}$ do Padre; palabras que no han llenado de una firmíssima esperanza de volver a ver lo que fuimos; palabras que trascribimos a V.S. en la inteligencia de que para los padres de la Compañia de Jesus, nada, nada tenemos reservado, nuestros brazos son para trabajar en la fabrica de los colegios, $\mathrm{y}$ todo lo que reditue nuestra labranza, nuestra factoria, y nuestra industria sera para depositarlo en mano de esos heroes que han sido nuestros verdaderos padres, $\mathrm{y}$ que quiza el fervor infatigable con que defendían nuestros derechos y nuestra livertad, ha sido el principal crimen que motivo su destierro y extinción en el siglo pasado.

Dios guarde a V.S. m. s.z.s.

* Instituto de Formación Docente

97000 Durazno -

Uruguay

\section{NOTAS}

1. Una excepción, pues contamos con la versión original en guaraní, : Alberto Palomeque. Un documento en Guaraní. In: Revista Epoca Moderna, T.XI. Montevideo, agosto. 1903.

2. Cordón de Montevideo. 20 de Febrero de 1857, 24 págs. El ejemplar que utilizamos se halla en la Bibl. Nacional de Mdeo. Colec. Melían Lafinur, T. 33.

3. Ob. cit, p. 2 .

4. Memoria de De Moussy VII, p.27. Cit. por De la Sota, ob. cit., p.14.

5. Ob. cit., p. 15 .

6. Consultar: Agustín Beraza. Rivera y la independencia de las Misiones. Montevideo, 1971 , p. 29 y ss.

7. Consultar: Oscar Padrón Favre. Sangre indigena en el Uruguay. Montevideo, 1986, p. 77 y ss.

8. Arch. Gral. Nación. Montevideo. Ex Arch. y Museo Hist. Nac. Caja 21.

9. Idem. idem. idem. Particulares Caja 6, Carp. 2.

10. Idem. idem. idem. Particulares Caja 6, Carp. 2, Doc. 21. 